\title{
Disruptive Effects of Tris and Sodium Lauroyl Sarcosinate on the Outer Membrane of Pseudomonas cepacia Shown by Fluorescent Probes
}

\author{
By HOSMIN ANWAR, MICHAEL R. W. BROWN, * ADAM Z. BRITTEN \\ AND PETER A. LAMBERT \\ Microbiology Research Group, Department of Pharmacy, University of Aston in Birmingham, \\ Birmingham B4 7ET, U.K.
}

(Received 26 November 1982; revised 9 February 1983)

\begin{abstract}
The disruptive effects of Tris buffer and sodium lauroyl sarcosinate (Sarkosyl) on the outer membrane (OM) of Pseudomonas cepacia were investigated with several fluorescent probes. Tris increased the permeability of the OM to 6-anilino-1-naphthalenesulphonic acid and 2-ptoluidinylnaphthalene-6-sulphonate. The degree of damage to the OM was enhanced when the $\mathrm{pH}$ was decreased. 3-( $\mathrm{N}$-morpholino)propanesulphonic acid buffer had a small but significant effect at acid $\mathrm{pH}$, while citrate/phosphate buffer showed insignificant effects. Sarkosyl released 3,3'-dipentyloxacarbocyanine iodide $\left(\mathrm{CC}_{5}\right)$ from $\mathrm{CC}_{5}$-labelled $\mathrm{OM}$ or whole cells and altered OM fluidity as studied by fluorescence polarization.
\end{abstract}

\section{INTRODUCTION}

The outer membrane (OM) of Gram-negative bacteria acts as a permeability barrier for the penetration of drugs (Brown, 1975; Nikaido \& Nakae, 1979). Hydrophobic compounds are unable to penetrate the $O M$ of some strains, because the outer leaflet is covered with hydrophilic, closely stacked and highly charged lipopolysaccharide (Nikaido \& Nakae, 1979; Shales \& Chopra, 1982). Hydrophilic compounds penetrate the OM by diffusion through the pore-forming proteins (porins) embedded in the membrane. However, there is a size limit for the penetration through the porins. Molecules larger than about 600 daltons are unable to diffuse through the porins in Enterobacteriaceae (Nikaido \& Nakae, 1979). Treatment of bacteria with EDTA has been shown to increase permeability to a large number of compounds (Leive, 1968). This is probably due to the removal of some of the lipopolysaccharide from the outer leaflet of the OM resulting in the redistribution of the phospholipids from the inner leaflet to the outer leaflet of the membrane (Nikaido \& Nakae, 1979).

Fluorescence probing has been widely accepted as a tool for the investigation of membrane structure and function (Radda, 1975; Azzi, 1975). Much information on the properties of the biological membranes such as polarity, microviscosity and lipid-phase transition has been obtained through this technique (Trauble \& Overath, 1973; Cheng et al., 1974). The mechanisms of action of antibiotics such as polymyxin (Hartmann et al., 1978; Newton, 1954) and colicins (Helgerson et al., 1974) have also been studied with fluorescent probes. Tris has been reported to damage the OM (Voss, 1967; Irvin et al., 1981). Sodium lauroyl sarcosinate (Sarkosyl) is a detergent that is commonly used in the preparation of the OM of Gram-negative bacteria, since it selectively solubilizes the cytoplasmic membrane (Filip et al., 1973). Recently, Sarkosyl was reported to remove several minor OM proteins from the OM of Escherichia coli

\footnotetext{
Abbreviations: OM, outer membrane; ANS, 6-anilino-1-naphthalenesulphonic acid; $\mathrm{CC}_{5}, 3,3^{\prime}$-dipentyloxacarbocyanine iodide; DPH, 1,6-diphenyl-1,3,5-hexatriene; MOPS, 3-( $N$-morpholino)propanesulphonic acid; TNS, 2-p-toluidinylnaphthalene-6-sulphonate.
} 
(Chopra \& Shales, 1980). This study shows the disruptive effects of both Tris and Sarkosyl on the cell envelope of Pseudomonas cepacia by the use of several fluorescent probes.

\section{METHODS}

Bacteria and culture conditions. The organism used throughout this study was Pseudomonas cepacia NCTC 10661. Organisms were grown at $37^{\circ} \mathrm{C}$ in 5-1 conical flasks containing 21 nutrient broth or chemically defined medium consisting of : glucose, $20 \mathrm{mM} ; \mathrm{KCl}, 3 \mathrm{~mm} ; \mathrm{NaCl}, 3 \mathrm{~mm} ;\left(\mathrm{NH}_{4}\right)_{2} \mathrm{SO}_{4}, 12 \mathrm{mM} ; \mathrm{MgSO}_{4}, 3 \cdot 2 \mathrm{mM} ; \mathrm{K}_{2} \mathrm{HPO}_{4}, 1 \cdot 2 \mathrm{mM}$; $\mathrm{FeSO}_{4}, 0.02 \mathrm{mM} ; 3$-( $N$-morpholino)propanesulphonic acid (MOPS), $50 \mathrm{~mm}$; the pH was adjusted to 7.4 with $\mathrm{NaOH}$. All chemicals were Analar grade (BDH). Vigorous aeration of the culture was achieved with a magnetic stirrer.

Chemicals. 2-p-Toluidinylnaphthalene-6-sulphonate (potassium salt) (TNS) and 6-anilino-1-naphthalenesulphonic acid (ANS) were obtained from Sigma. 2-Methylanthracene and 1,6-diphenyl-1,3,5-hexatriene (DPH) were obtained from Aldrich. The fluorescent properties of the probes used in this study have been described previously (Azzi, 1975; Radda, 1975; Shinitzky \& Barenholz, 1978).

Preparation of the $O M$ of $P$. cepacia. The $\mathrm{OM}$ was prepared by sucrose density gradient centrifugation as described by Anwar et al. (1983).

Effects of $p H$ and buffer systems on the fluorescence of TNS or ANS. Several buffer systems such as Tris/maleate buffer (Gomori, 1948), citrate/phosphate buffer (McIlvaine, 1921) and MOPS buffer were used. MOPS buffer (final concentration, $50 \mathrm{mM}$ ) was adjusted to an appropriate $\mathrm{pH}$ with $1 \mathrm{M}-\mathrm{NaOH}$.

The cells were grown in chemically defined medium and harvested at mid-exponential phase (optical density at $470 \mathrm{~nm}=0.5$ ) by centrifugation at $5000 \mathrm{~g}$ for $15 \mathrm{~min}$, washed twice with saline then resuspended in an appropriate buffer to give an $\mathrm{OD}_{470}$ of $0 \cdot 25$. The cell suspension $(4.9 \mathrm{ml})$ was transferred to a test tube and $0 \cdot 1 \mathrm{ml}$ of TNS or ANS (in ethanol) was added (final concentration, $10 \mu \mathrm{M}$ ). The cells were then incubated at $37^{\circ} \mathrm{C}$ for $15 \mathrm{~min}$ and the fluorescent spectra taken, using an Aminco-Bowman Spectrofluorimeter and a Hewlett Packard 7035B X-Y recorder.

Effects of Sarkosyl on the fluorescence of 3,3'-dipentyloxacarbocyanine iodide $\left(C C_{5}\right)$ in the $O M$ and whole cells of $P$. cepacia. The $\mathrm{OM}$ isolated as above or the whole cells (grown in nutrient broth) were treated with $\mathrm{CC}_{5}$ (in ethanol; final concentration, $2 \mu \mathrm{M}$ ), incubated for $15 \mathrm{~min}$, centrifuged at $38000 \mathrm{~g}$ for $1 \mathrm{~h}$, and washed once with distilled water. They were treated with Sarkosyl (final concentration, $2 \%$, w/v) or left untreated (control) for 30 min at room temperature, and then centrifuged at $38000 \mathrm{~g}$ for $1 \mathrm{~h}$. The supernate was collected and the pellet was resuspended in the same volume of distilled water $(10 \mathrm{ml})$. Fluorescent spectra of the supernate (Sarkosyl-soluble material) and pellet (Sarkosyl-insoluble material) of both samples were taken.

Effect of Sarkosyl on the fluorescence polarization of the OM of P. cepacia. OM suspensions treated with Sarkosyl (final concentration, $2 \%$ ) as described above or untreated were resuspended in distilled water and adjusted to an $\mathrm{OD}_{470}$ of $0 \cdot 2$. An appropriate fluorescent probe solution $(0.25 \mathrm{ml})$ was added to $24.75 \mathrm{ml}$ of the cell suspension (final concentration of probe, $5 \mu \mathrm{M}$ ), which was then incubated for $15 \mathrm{~min}$ at $37^{\circ} \mathrm{C}$, centrifuged at $38000 \mathrm{~g}$ for $60 \mathrm{~min}$, washed once with distilled water and resuspended in $25 \mathrm{ml}$ of distilled water. Fluorescence polarization was measured as described by Gratzel \& Thomas (1973). Microviscosity was calculated from the fluorescence polarization measurement of DPH as described by Shinitzky \& Barenholz (1978).

\section{RESULTS AND DISCUSSION}

\section{Effects-of pH and buffer systems on the fluorescence of TNS or ANS in P. cepacia}

It was reported by Ballard et al. (1972), using Tris, that fluorescence of ANS in the presence of $E$. coli increased as the $\mathrm{pH}$ was decreased. We also found that the fluorescence of TNS or ANS increased as the $\mathrm{pH}$ decreased from $7 \cdot 4$ to 5.2 (Fig. 1). However, a large increase in the fluorescence intensity of ANS could only be observed when Tris buffer was used. Similar results were obtained with TNS (data not shown). MOPS had a small but significant effect at acid $\mathrm{pH}$, while citrate/phosphate buffer showed insignificant increases in the fluorescence intensity (data not shown). This study confirms the observations of other workers (Voss, 1967; Irvin et al., 1981) that Tris damages the OM, probably by breaking the salt-bridges formed between divalent metal cations such as magnesium and structural components such as lipopolysaccharide and releases these components as has been suggested by Voss (1967). This effect of Tris is enhanced when the $\mathrm{pH}$ is decreased. There are no previous reports of MOPS acting in this way.

\section{Effect of Sarkosyl on the cell envelope of $P$. cepacia}

Filip et al. (1973) found that Sarkosyl specifically solubilized the cytoplasmic membrane of $E$. coli, leaving the OM relatively intact. Their conclusion was based on the similarity of the OM 


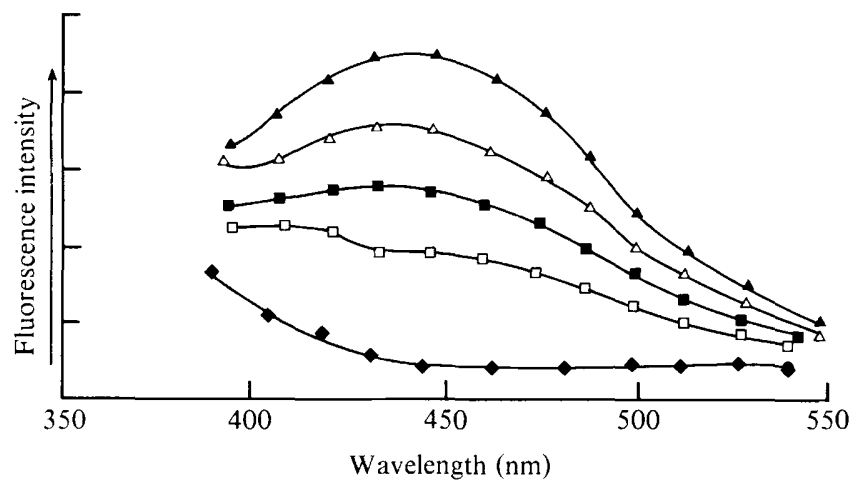

Fig. 1. Effects of $\mathrm{pH}$ in Tris/maleate buffer on fluorescence of ANS in $P$. cepacia NCTC 10661. $\Delta, \mathrm{pH} 5.2 ; \triangle, \mathrm{pH} 6.2 ; \square, \mathrm{pH} 6.6 ; \square, \mathrm{pH} \mathrm{7.0;}, \mathrm{pH} \mathrm{7.4.} \mathrm{Excitation} \mathrm{wavelength} \mathrm{of} \mathrm{ANS} \mathrm{at}$ $355 \mathrm{~nm}$.

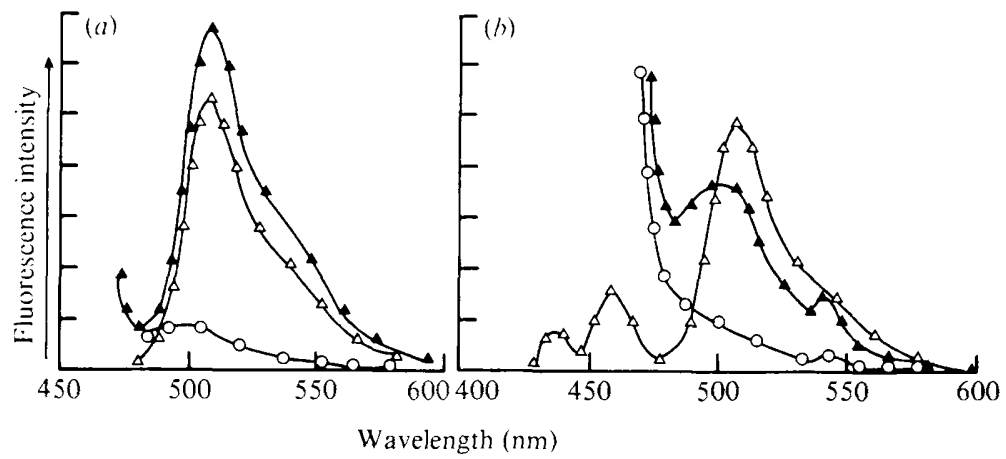

Fig. 2. Effects of Sarkosyl on fluorescence of $\mathrm{CC}_{5}$ in $(a)$ the OM and $(b)$ whole cells of $P$. cepacia NCTC 10661. $\triangle$, OM (in $a$ ) or whole cells (in $b$ ); $\triangle$, Sarkosyl-soluble material; $O$, Sarkosyl-insoluble material. Excitation wavelength of $\mathrm{CC}_{5}$ at $470 \mathrm{~nm}$.

protein patterns obtained by the sucrose density gradient centrifugation and Sarkosyl methods. However, Chopra \& Shales (1980) found that several minor OM proteins were extracted by Sarkosyl treatment. In the present study, both OM and whole cells of $P$. cepacia were treated with $\mathrm{CC}_{5}$, and these samples were then extracted with Sarkosyl. The results showed that $\mathrm{CC}_{5}$ was released from both the OM and the whole cells by Sarkosyl (Fig. 2). If Sarkosyl had no effect on the $\mathrm{OM}$, then the complete disappearance of the fluorescence of $\mathrm{CC}_{5}$ from the $\mathrm{OM}$ or whole cells would not be observed. The location of $\mathrm{CC}_{5}$ in the $\mathrm{OM}$ or whole cell is thus accessible to Sarkosyl. The mechanism probably involves penetration of Sarkosyl into the OM or whole cells, followed by partitioning of solubilized $\mathrm{CC}_{5}$ into the aqueous phase. The effect of Sarkosyl on the OM was also studied by fluorescence polarization (Table 1). The fluorescence polarization of the $\mathrm{OM}$ increased about twofold following Sarkosyl treatment as studied with $\mathrm{CC}_{5}$ and 2-methylanthracene, and the microviscosity of the $\mathrm{OM}$ increased by approximately 0.5 poise $(0.05 \mathrm{~Pa} \cdot \mathrm{s})$ following Sarkosyl treatment as studied with DPH.

We conclude that Tris damages the OM of P. cepacia, and increases its permeability to ANS or TNS. The degree of damage can be enhanced by decreasing the $\mathrm{pH}$. In this study, Sarkosyl removed $\mathrm{CC}_{5}$ from the $\mathrm{OM}$ or intact cells of $P$. cepacia and caused changes in the fluidity of the OM. Sarkosyl should not be used in the preparation of the OM for the study of physical properties. If it is used in chemical studies of OM preparations, it is likely to remove some proteins from the OM, and great care in interpretation of results is required (Chopra \& Shales, 1980). 
Table 1. Effects of Sarkosyl on fluorescence polarization and microviscosity of the OM from $P$. cepacia NCTC 10661 grown in nutrient broth

The data are means of three determinations \pm S.D. Microviscosity is expressed in poise ( 1 poise $=$ $0 \cdot 1 \mathrm{~Pa} \cdot \mathrm{s})$. Excitation and measured emission were: $470 \mathrm{~nm}$ and $505 \mathrm{~nm}$ for $\mathrm{CC}_{5}, 365 \mathrm{~nm}$ and $430 \mathrm{~nm}$ for $\mathrm{DPH}$, and $375 \mathrm{~nm}$ and $435 \mathrm{~nm}$ for 2-methylanthracene.

\begin{tabular}{|c|c|c|c|c|}
\hline \multirow[b]{2}{*}{ Probe } & \multicolumn{2}{|c|}{ Sarkosyl-treated OM } & \multicolumn{2}{|c|}{ Untreated OM } \\
\hline & $\begin{array}{l}\text { Fluorescence } \\
\text { polarization }\end{array}$ & Microviscosity & $\begin{array}{l}\text { Fluorescence } \\
\text { polarization }\end{array}$ & Microviscosity \\
\hline $\mathrm{CC}_{5}$ & $0 \cdot 22 \pm 0 \cdot 01$ & - & $0.12 \pm 0.02$ & - \\
\hline DPH & $0.37 \pm 0.02$ & $2 \cdot 06 \pm 0.07$ & $0.30 \pm 0.02$ & $1.55 \pm 0.09$ \\
\hline 2-Methylanthracene & $0.22 \pm 0.03$ & - & $0.13 \pm 0.01$ & - \\
\hline
\end{tabular}

\section{REFERENCES}

Anwar, H., Brown, M. R. W., Cozens, R. M. \& LAMBERT, P. A. (1983). Isolation and characterization of the outer and cytoplasmic membranes of Pseudomonas cepacia. Journal of General Microbiology 129, 499-507.

AzZI, A. (1975). The application of fluorescent probes in membrane studies. Quarterly Reviews of Biophysics 8, 237-316.

Ballard, S. G., Barker, R. W., Barrett Bee, K. J., DWEK, R. A., Radda, G. K., SMITH, D. S. \& TAYLOR, J. A. (1972). The location and response of probes in membranes. In Biochemistry and Biophysics of Mitochondrial Membranes, pp. 257-275. Edited by E. Carafoli, E. Qualiariello, G. F. Azzone, A. L. Lehninger \& N. Siliprandi. London: Academic Press.

Brown, M. R. W. (1975). The role of the cell envelope in resistance. In Resistance of Pseudomonas aeruginosa, pp. 71-107. Edited by M. R. W. Brown. London: John Wiley.

Cheng, S., Thomas, J. K. \& Kulpa, C. F. (1974) Dynamics of pyrene fluorescence in Escherichia coli. Biochemistry 13, 1135-1139.

Chopra, I. \& Shales, S. W. (1980). Comparison of the polypeptide composition of Escherichia coli outer membranes prepared by two methods. Journal of Bacteriology 144, 425-427.

Filip, C., Fletcher, G., WulfF, J. L. \& Earhart, C. F. (1973). Solubilisation of the cytoplasmic membrane of Escherichia coli by the ionic detergent sodium-lauryl sarcosinate. Journal of Bacteriology $115,717-722$.

GOMORI, G. (1948). Histochemical demonstration of sites of choline esterase activity. Proceedings of the Society for Experimental Biology and Medicine 68, 354-358.

Gratzel, M. \& Thomas, J. K. (1973). On the dynamics of pyrene fluorescence quenching in aqueous ionic micellar systems. Factors affecting the permeability of micelles. Journal of the American Chemical Society 95, 6885-6889.

HartmanN, W., Galla, H. J. \& Sackmann, E. (1978). Polymyxin binding to charged lipid membranes. An example of cooperative lipid-protein interaction. Biochimica et biophysica acta 510, 124-139.
Helgerson, S. L., Cramer, W. A., Harris, J. M. \& LYLE, F. E. (1974). Evidence of a microviscosity increase in the Escherichia coli cell envelope caused by colicin E1. Biochemistry 13, 3057-3061.

Irvin, R. T., MCAlistar, T. J. \& COSTerton, J. W. (1981). Tris(hydroxymethyl)aminomethane modifcation of Escherichia coli outer membrane permeability. Journal of Bacteriology 145, 13971403.

LeIve, L. (1968). Studies on the permeability change produced in coliform bacteria by ethylene diamine tetra-acetate. Journal of Biological Chemistry 243, 2373-2380.

MCIlvaine, T. C. (1921). A buffer solution for colorimetric comparison. Journal of Biological Chemistry 49, 183-186.

Newton, B. A. (1954). Site of action of polymyxin on Pseudomonas aeruginosa: antagonism by cations. Journal of General Microbiology 10, 491-499.

NikaIdo, H. \& NAKaE, T. (1979). The outer membrane of Gram-negative bacteria. Advances in Microbial Physiology 20, 163-250.

RADDA, G. K. (1975). Fluorescence probes in membrane studies. In Methods in Membrane Biology, vol. 4, pp. 97-188. Edited by E. D. Korn. New York: Plenum Press.

Shales, S. \& Chopra, I. (1982). Outer membrane composition of Escherichia coli and the poor activity of hydrophobic antibiotics against enteric bacteria. Journal of Antimicrobial Chemotherapy 9, 325326.

ShINITZKY, M. \& Barenholz, Y. (1978). Fluidity parameters of lipid regions determined by fluorescence polarization. Biochimica et biophysica acta $\mathbf{5 1 5}$, 367-394.

Trauble, H. \& Overath, P. (1973). The structure of Escherichia coli membrane studied by fluorescence measurement of lipid-phase transitions. Biochimica et biophysica acta 307, 491-512.

Voss, J. G. (1967). Effects of organic cations on the Gram-negative cell wall and their bactericidal activity with ethylene diamine tetra-acetate and surface active agents. Journal of General Microbiology 48, 391-400. 